\title{
Exposición sobre la Antártica del señor Ministro de Relaciones Exteriores, don Raúl Juliet Gómez, ante el Senado de la República de Chile, en sesión extraordinaria de fecha 21 de enero de $1947^{1}$
}

\author{
Speech on Antarctica of the Minister of Foreign Affairs Mr. Raúl Juliet
}

Gómez in the Chilean Senate, in extraordinary session of January 21 ${ }^{\text {th }}, 1947$

\begin{abstract}
Nota del Editor: Al conmemorarse 70 años desde el establecimiento de la primera base chilena antártica, entonces llamada Base Soberanía, hoy Base Prat, ha parecido relevante publicar el texto de la exposición hecha ante el Senado el 21 de enero de 1947 por el entonces Canciller del gobierno del Presidente Gabriel González Videla. En ella se hace una revisión general tanto de los fundamentos de los derechos antárticos chilenos como de las actividades realizadas al respecto en aquellos años, entre otras, la expedición que establecería la citada base. En 1948, el Presidente González Videla sería el primer Jefe de Estado del mundo en llegar hasta la Antártica, visitaría la Base Soberanía e inauguraría una segunda estación chilena, la Base O’Higgins.
\end{abstract}

"Señor Presidente,

Honorable Senado:

Deseo referirme a una materia a la cual el Gobierno ha concedido siempre gran importancia y que actualmente preocupa a muchas naciones extranjeras.

Analizaré aquí los derechos de soberanía que Chile posee en la Antártica, derechos tan firmes e indiscutibles, que nos hacen mirar no sin cierto recelo lo que se ha dado en llamar "la carrera al Polo Sur".

En el año 1940, el Gobierno dictó, por intermedio del Ministerio de Relaciones Exteriores, un decreto supremo que precisó los límites del Territorio Chileno Antártico o Antártica Chilena. Tal medida se adoptó después de un estudio muy completo de todos nuestros títulos y de compulsar numerosos documentos de orden histórico, geográfico, jurídico, diplomático y administrativo, que se conservan en la Cancillería y en otras reparticiones públicas.

${ }^{1}$ El texto transcrito fue publicado como Soberanía de Chile en la Antártica (Santiago: Imprenta Chile, 1948).

Número de página no utilizable para citar 
En efecto, tan pronto como asumió el poder el recordado Presidente Aguirre Cerda, que a través de su dilatada vida pública y de sus profundos estudios acerca de nuestro país había comprendido la importancia y el interés que tenían para Chile las tierras situadas al sur del Cabo de Hornos, dio instrucciones precisas a fin de que el Ministerio de Relaciones Exteriores determinara los antecedentes probatorios de nuestro dominio antártico, y señalara los límites del territorio polar que pertenece a la República. Con este objeto, en virtud del Decreto Supremo No 1.541 , de 7 de septiembre de 1939, creó la Cancillería una Comisión Especial que, previos los estudios pertinentes, señalaría dichos límites.

Al cabo de más de un año de acuciosas búsquedas en archivos y bibliotecas, estuvo esta comisión en condiciones de solicitar del Gobierno la dictación del Decreto Supremo N 1.747 , de fecha 6 de noviembre de 1940.

Voy a permitirme dar lectura a este Decreto, atendida su importancia. Dice así:

"Santiago, 6 de noviembre de 1940.

\section{CONSIDERANDO:}

Que es deber del Estado fijar con exactitud sus límites territoriales;

Que no se han precisado hasta ahora los límites del territorio chileno en la parte que se prolonga hasta la región polar denominada Antártica Americana;

Que este Ministerio dejó públicamente constancia, en 1906, que la delimitación del referido territorio era materia de estudios iniciados, pero todavía no completos;

Que el actual estado de tales estudios permite tomar ya una determinación al respecto;

Que la Comisión Especial nombrada por el Decreto de este Ministerio $\mathrm{N}^{\mathrm{o}} 1.541$, de 7 de septiembre de 1939, ha establecido los límites del territorio chileno antártico en conformidad a los datos que suministra los antecedentes geográficos, históricos, jurídicos y diplomáticos compulsados y que se han venido acumulando hasta la fecha

\section{DECRETO:}

Forman la Antártica Chilena o Territorio Chileno Antártico todas las tierras, islas, islotes, arrecifes, glaciares (pack-ice) y demás conocidos y por conocerse, y el mar territorial respectivo, existente dentro de los límites del casquete constituido por los meridianos 53, longitud oeste de Greenwich y 90 longitud oeste de Greenwich.

Tómese razón, comuníquese, publíquese e insértese en el Boletín de Leyes y Decretos del Gobierno -Aguirre Cerda. - Marcial Mora M.” 
Llamo la atención de los señores Senadores hacia la circunstancia de que el decreto a que acabo de dar lectura, no crea títulos a favor de nuestro país sobre el casquete aludido, ni pretendió crearlos. Al dictársele, no se tuvo en vista mejorar nuestro dominio o allegar un nuevo derecho a los que ya poseíamos. No; simplemente se quiso precisar, como en él se dice, los límites de un territorio que era chileno en virtud de bien fundados antecedentes.

En obsequio al orden y a la claridad, no me ocuparé aquí de la repercusión internacional que esta medida del Gobierno originó.

Me referiré antes, aunque sea en forma sumaria, a los antecedentes que la Cancillería tuvo en vista para señalar las fronteras de Chile en esa región polar que constituye la natural prolongación del suelo patrio.

Tales antecedentes son, como lo expresé anteriormente, de carácter histórico, geográfico, jurídico, diplomático y administrativo, y en el mismo orden me ocuparé separadamente de ellos.

\subsection{Antecedentes históricos}

Los títulos de orden histórico que puede ostentar la República sobre su casquete polar, se confunden, Honorable Senado, con el descubrimiento de Chile.

No deseo fatigar la atención de los señores Senadores con un estudio, que necesariamente debe ser extenso, sobre las numerosas reales cédulas y órdenes de la Corona de Castilla, referentes a los territorios situados entre la ribera Sur del Estrecho de Magallanes y el Polo Antártico, los cuales, durante los tres siglos de dominación española, cayeron en la demarcación del Reino de Chile. Me limitaré a trazar un breve bosquejo histórico que dejará en el ánimo del Honorable Senado -estoy seguro de ello- el convencimiento de que, aparte de los demás, los antecedentes coloniales son títulos legítimos e inmejorables.

Es indispensable, previamente, conocer el concepto que en aquella época se tenía de las tierras australes que enfrentaban al continente americano recién descubierto. Era creencia general la de que más allá del Estrecho se extendía un vasto territorio que, atravesando el Polo, se prolongaba hasta el Reino de la China. Este territorio quedaba bajo la soberanía de la España de los descubrimientos. Así lo señalaron los geógrafos y cartógrafos en todos los mapas y cartas dibujadas en los siglos XVI y XVII, y así lo demuestran los testimonios históricos de los cronistas más autorizados de aquel entonces.

Con respecto a los mapas y cartas, señores Senadores, se ha confeccionado en la Cancillería la nómina -que tengo aquí a mano-, de los más importantes. Ella abarca 39 documentos de esta 
especie. En todos aparece a continuación del Estrecho, un extenso Continente denominado unas veces “Terra Australis” y otras “Terra Magallánica”.

En lo que a los cronistas se refiere, citaré solamente el testimonio de don Antonio de Herrera, que poseía el cargo oficial de cronista de Indias, y que en su famosa obra sobre la "Descripción de las Indias Occidentales" expresa:

"Todo el dicho mar (del Sur), sus riberas y tierras, caen en la demarcación de la Corona de Castilla y de León, y todo lo demás que está por descubrir en este mar, desde la línea equinoccial hasta el Polo Antártico, que es el Polo del Sur, asimismopertenece a la Corona de Castilla".

Sobre la base de éstos y otros títulos y antecedentes, los soberanos españoles otorgaron concesiones a los conquistadores. En efecto, con fecha 24 de enero de 1539, el Emperador Carlos V capituló con Pedro Sancho de Hoz, confiriéndole en gobernación, todas las tierras "que están de la otra parte del Estrecho" de Magallanes, y constituyéndole así en el primer mandatario de los territorios antárticos.

Un año después, en 1540, inició Pedro de Valdivia la conquista de Chile. Su propósito era el de ocupar toda la región que se prolongaba al Sur de la Gobernación del Perú, y emprendió viaje con Pedro Sancho de Hoz, el concesionario de la Antártica, al cual se había unido en sociedad. Ocurrió que, durante el viaje, y al cabo de las variadas incidencias entre ambos conquistadores de que nos habla la historia, Hoz renunció en favor de Valdivia a todos los derechos que le había otorgado el Emperador. La escritura en que consta tal renuncia, fue extendida en el pueblo de Atacama, con fecha 12 de agosto de 1540, ante el escribano público Luis de Cartagena.

Valdivia, en consecuencia, llegó a reunir bajo su mando los territorios de la Gobernación de la "Nueva Extremadura", cuyo límite meridional fue fijado posteriormente en el grado 41 de latitud sur, y los de la Gobernación de la "Terra Australis", cuyo límite septentrional lo constituía la ribera Sur del Estrecho de Magallanes.

Las provincias sujetas a la jurisdicción de Valdivia quedaban, sin embargo, interrumpidas por una ancha faja de tierra que era necesario incorporar a su mandato para obtener la continuidad del país. Fue así, Honorable Senado, como Valdivia envió a España, en 1553, a su teniente Jerónimo de Alderete, con el encargo de obtener para sí la ampliación de Nueva Extremadura hasta el Estrecho de Magallanes. Su petición fue favorablemente acogida y el 29 de septiembre de 1554, una Real Cédula de Carlos V ensanchaba la Gobernación de Valdivia en la forma solicitaba por éste.

La consolidación de estas tres secciones del territorio chileno, bajo la jurisdicción de un mandatario único, vino a producirse ocho meses más tarde, esto es, con el nombramiento del mismo Alderete como Gobernador de Chile, pues éste, entre tanto, había obtenido su designación como Gobernador de la "Tierra Australis".

Número de página no utilizable para citar 
A contar de 1555, el territorio chileno, desde el Perú hasta el Polo Antártico, mantuvo su continuidad geográfica, y todos los Gobernadores del Reino que sucedieron a Alderete, de don García Hurtado de Mendoza a don Mateo de Toro Zambrano, ejercieron jurisdicción sobre la integridad de dicho territorio, sin interrupción alguna. Las diversas reales órdenes de nombramiento así lo demuestran fehacientemente.

No varió esta situación por la circunstancia de haber sido descubierto el llamado Estrecho de Drake, brazo marítimo que separa la Tierra del Fuego de la región antártica, y que el corsario que le dio su nombre fue el primero en navegaren 1578. Y digo que no varió, porque, sin los conocimientos geográficos actuales, las Reales Cédulas hablaban simplemente de las tierras situadas de otro lado del Estrecho, y ninguna importancia reviste para el caso, el hecho de que esas tierras estuviesen atravesadas por algún estrecho o paso de mar, como lo es el de Drake.

Producida la independencia de los países americanos, éstos aceptaron para los efectos de determinar sus fronteras, como bien lo saben los Honorables Senadores, el uti-possidetis de 1810, es decir, los límites asignados por la Metrópoli a las diferentes secciones administrativas del Continente. Chile nació, pues, a la vida libre, poseyendo un territorio que comprendía la natural prolongación del país hacia el polo.

O’Higgins, Padre de la Patria, en un memorable documento histórico, declara que, en efecto, la soberanía de la nación a la que él dio libertad alcanzaba a las tierras antárticas. Su calificado testimonio es de inapreciable valor. En carta escrita desde Lima, durante su destierro, y fechada el 20 de agosto de 1831, envía a su amigo, el Capitán Coghland, de la Real Armada Británica, un trabajo titulado "Bosquejo Comparativo de las ventajas naturales y de otra especie, que poseen los Estados Unidos y Chile, respectivamente, para constituir una potencia marítima de primera clase en el Nuevo Mundo".

Me será grato, señores Senadores, leer algunos párrafos de este interesantísimo documento, que fuera encontrado en 1918, en los archivos del Foreign Office, por el señor don Carlos Silva Vildósola, y del cual la Cancillería obtuvo una copia fotográfica gracias a la benevolencia del Gobierno inglés.

Dice O’Higgins, refiriéndose a nuestro país:

"Chile, viejo y nuevo se extiende en el Pacífico desde la bahía de Mejillones hasta Nueva Shetland del Sur, en latitud 65 grados sur; y en el Atlántico, desde la península de San José en latitud 42 grados, hasta Nueva Shetland del Sur, o sea, 23 grados que añadidos a 42 grados en el Pacifico, hacen 65 grados, o sea, 3900 millas geográficas, con una superabundancia de excelentes puertos en ambos océanos, y todos ellos salubres en todas las estaciones". 
Y continúa más adelante:

"Tampoco hay en toda la Unión Americana una sola posición que pueda llamarse la llave del Atlántico o del Pacífico, mientras que Chile posee evidentemente la llave del Atlántico desde el grado 30 de latitud sur hasta el Polo Antártico y la de todo el gran Pacífico".

Las palabras de O’Higgins, señor Presidente, son elocuentes y claras. Chile, según ellas, abarca hasta el Polo Antártico, en consonancia con lo establecido por los numerosos antecedentes históricos de la época colonial.

La soberanía de nuestro país en la región antártica no fue alterada por el arreglo de fronteras que convinimos, años más tarde, con la Republica de Argentina. El Tratado de Límites de 23 de julio de 1881 que suscribimos con esa República, no se refirió a la zona polar, pues el litigio fronterizo estaba circunscrito únicamente a los territorios situados en el continente americano, hasta el Cabo de Hornos.

De ello da fe el texto del propio Tratado y la circunstancia de que, algunos años después, en 1906, Chile y la República Argentina entrasen en negociaciones para firmar un nuevo convenio referente a su frontera común en la región antártica, cuyo proyecto lleva el título de "Tratado complementario de demarcación de límites".

Efectivamente, en el año indicado, mi ilustre predecesor en el Ministerio de Relaciones Exteriores, don Antonio Huneeus Gana, inició conversaciones con el Ministro argentino en Santiago, doctor don Lorenzo Anadón, a fin de llegar a determinar el límite chileno-argentino en la zona polar sur. La Memoria de la Cancillería correspondiente a 1906 expresó a este respecto, con la discreción propia de la índole de las gestiones que se llevaban a efecto, los siguientes conceptos:

"Nuestras relaciones con la República Argentina han progresado en cordialidad, y en nada la menoscaban las diferencias subsistentes acerca de la determinación de nuestra frontera en el Canal de Beagle y acerca de algunas posesiones en la región polar".

"Los territorios antárticos en estudio son materia propia de exploraciones aun no completas, que urge estimular y a las cuales se habrán de seguir avenimientos que todo hace fáciles entre los Gobiernos chileno y argentino".

Las conversaciones comenzadas por el señor Huneeus Gana continuaron bajo el Ministerio de su sucesor, doctor don Federico Puga Borne, y con tan buen éxito que se llegó a redactar el texto de un convenio que, según he dicho, lleva por título el de "Tratado complementario de demarcación de límites". 
De acuerdo con este tratado cuyo proyecto original se guarda en la Cancillería, Chile y la República Argentina determinan sus límites tanto en el Canal de Beagle como en la zona antártica.

Las gestiones a que vengo refiriéndome quedaron paralizadas con motivo de la dimisión del Ministro de Relaciones Exteriores argentino, doctor don Estanislao S. Zeballos, ocurrida en 1908. Posteriormente, abandonó también el Ministerio el doctor Puga Borne, y la negociación no se llevó adelante.

El arreglo proyectado partía de la base de que ambos países interesados gozaban de derechos en la región polar y, sobre dicha base, se trazaba una línea divisoria que, pasando entre las Islas Shetlands y las Orcadas del Sur, llegaba hasta el mismo Polo Antártico.

En todo caso, señores Senadores, las conversaciones de que he hecho mención, aun cuando no alcanzaron resultados positivos y se llevaron a efecto con carácter reservado, tienen el valor indudable de un reconocimiento, por parte de la República Argentina, de los claros derechos de Chile a la zona polar.

\subsection{Antecedentes geográficos}

No son menos claros, señor Presidente, los antecedentes de orden geográfico que abonan nuestra soberanía sobre el sector antártico chileno.

Tales antecedentes se basan en particular en dos conceptos de mucha importancia: el de la continuidad y el de la contigüidad geográficas.

El concepto de la continuidad geográfica tiene perfecta aplicación en el caso de la Antártica Chilena con respecto al extremo meridional del continente americano.

En efecto, desde el punto de vista geográfico, la Tierra de O’Higgins, esto es, aquella angosta lengua de tierra antártica situada entre los meridianos $55^{\circ}$ y $70^{\circ}$ de longitud oeste de Greenwich y que se halla recorrida en todo su largo por una cadena de montañas, constituye la prolongación del territorio continental americano. Esto que afirmo no es una mera suposición teórica. Es algo comprobado científicamente, y acerca de lo cual no hay discrepancias entre los técnicos.

La sola mirada a una carta geográfica nos hace comprender esta verdad. La América meridional es el continente que más se extiende hacia el sur del globo, y, por su parte, la Tierra de O’Higgins es la masa de tierras antárticas que más avanza hacia el norte, a tal punto que el llamado Estrecho de Drake es el más angosto entre toda la Antártica y el resto del Mundo.

Esta curiosa apariencia ha hecho decir a los geólogos de la Universidad de Cambridge, señores Priestley y Tilley: 
“Morfológicamente la Tierra de Graham (Tierra de O’Higgins) se yergue como la imagen de la Patagonia reflejada en un espejo, al otro lado de las profundas aguas del Estrecho de Drake. La cadena de islas de la Patagonia occidental (chilena) se refleja en las islas de su borden occidental. Esta simetría se revela aún más en la arquitectura geológica, pues la estructura geológica de la Patagonia se repite en la Península de la Tierra de Graham".

Los mismos conceptos exponen muchos otros sabios de diversas nacionalidades. Quiero solamente citar, de entre ellos, al geólogo y profesor sueco Juan Gunnar Anderson, quien ha expresado:

" $1{ }^{\circ}$ Los contornos y la orografía de la extremidad meridional de la América del Sur y de la Tierra de Graham (Tierra de O'Higgins) se parecen en tal forma, que se puede representar cualquiera de estos Continentes como un reflejo del otro.

$2^{\circ} \mathrm{La}$ estructura geológica es estrictamente simétrica.

$3^{\circ}$ La serie de capas del cretáceo superior y del terciario es la misma en la Patagonia y en la Tierra de Graham".

Observen los señores Senadores, que los geólogos que he citado no sólo se refieren a la semejanza morfológica -es decir, de forma- entre la extremidad americana y la extremidad antártica. Añaden que esta semejanza es aún geológica, esto es, semejanza de contextura terrestre.

La similitud geológica tiene una explicación científica. Se ha llegado a comprobar, mediante sondajes del Estrecho Drake, que Chile y la Antártica están unidos por una cordillera sumergida, que vendría a ser el lazo de vinculación entre la Cordillera de los Andes y los Antartandes, como se ha dado en denominar a la cadena de montañas que recorre la Tierra de O’Higgins.

Ruego a los Honorables Senadores se sirvan excusarme si nuevamente debo recurrir a las citas. Mis palabras, en estas materias, no tendrían suficiente valor si no las apoyara en las autorizadas afirmaciones de los técnicos. A propósito de esta unión de cordilleras a que acabo de aludir, dice el ilustre geólogo doctor don Juan Brüggen, por largos años profesor en la Universidad de Chile, que la Cordillera de los Andes no termina en la Tierra del Fuego, "sino que sigue como cordón submarino de 1.200 kilómetros de longitud que se distingue claramente hasta la línea de 3.000 metros de profundidad. De este cordón submarino se levanta el Banco de Burwood, con profundidades menores a 200 metros y con una longitud de 400 kilómetros”.

Dadas estas comprobaciones científicas, se cree fundadamente que en un tiempo remoto la América y la Antártica estuvieron unidas con continuidad terrestre, y que el hundimiento de las tierras que hoy forman el lecho del Mar de Drake se debe al mismo fenómeno, más pronunciado, que causó el cuasi hundimiento de la Cordillera de los Andes, en el extremo meridional de Chile, desde la isla de Chiloé hasta el Cabo de Hornos. 
Es sorprendente, Honorable Senado, la similitud física entre ambos continentes. La orografía de los territorios, la formación arenosa, la constitución volcánica, las características petrográficas y los análisis químicos que revelan que una misma vida animal y vegetal ha habitado ambas regiones, son valiosos elementos que vienen a dar poderosa fuerza a la hipótesis en cuestión.

Fuera de todo lo anterior, existen otros dos importantes factores científicos que pueden sumarse a los antecedentes de orden geográfico en favor de nuestro dominio polar. Me refiero a los aspectos climatérico y glaciológico.

Por lo que hace al primero, sabido es que la Antártica ejerce una influencia preponderante en el clima de Chile, mediante dos corrientes, marítima la una y aérea la otra, que nos envía el Continente Sur. La corriente marítima es la famosa corriente fría de Humboldt que tan sustancialmente modifica la temperatura de nuestro litoral, y la corriente aérea es la que continuamente está renovando la atmósfera de nuestro país.

En cuando al aspecto glaciológico, también es muy notable la semejanza entre los hielos y nieves antárticos y los que se forman en nuestro territorio continental, desde la Laguna de San Rafael hasta la Tierra del Fuego.

El Capitán de Navío de nuestra Armada, don Enrique Cordovez Madariaga, que ha estudiado a fondo el problema glaciológico de estas regiones, expresa al respecto:

“El parecido y, más que eso, el parentesco y muy próximo, que existe entre el territorio chileno y la Antártica tiene en sus nieves y hielos la razón tal vez más fundamental y convincente".

No voy a abundar, Honorable Senado, en las razones científicas que el Comandante señor Cordovez detalla magníficamente en su obra sobre la Antártica, porque seguramente dicha obra es conocida de todos los señores Senadores. Basta para el efecto dejar constancia de que el párrafo aludido está comprobado técnicamente en todos sus aspectos por el citado marino, abonando así esta continuidad glaciológica entre el territorio chileno y la zona antártica.

Como resultado de las investigaciones científicas a que, en forma tan sucinta, he aludido, llegamos a la conclusión de que el sector polar chileno es la natural prolongación de nuestro territorio continental. Si a ello agregamos que Chile es el país del mundo más cercano a la Antártica $-y$ he aquí el otro antecedente geográfico en favor nuestro: el de la contigüidad o vecindad-podemos afirmar perentoriamente que los títulos de carácter geográfico dan a la República derechos preferentes de soberanía sobre la zona polar delimitada por el Decreto Supremo de 1940. 


\subsection{Antecedentes jurídicos}

Analicemos ahora, señor Presidente, los antecedentes de orden jurídico que consolidan el dominio de Chile, en un sector del continente antártico.

Previamente, es necesario hacer algunas consideraciones acerca de la naturaleza del dominio en las regiones polares, a la luz del moderno Derecho Internacional.

Desde luego, cabe tener presente que, dadas sus peculiares características, no es posible aplicar a los territorios polares las normas jurídicas ordinarias para la adquisición del dominio.

Dejemos de lado el "descubrimiento", el cual, tanto en lo relativo al dominio polar como en lo tocante a toda otra especie de dominio en el campo del Derecho de Gentes, no constituye sino un título provisorio, un modo de adquirir precario, que vendrá a consolidarse, si concurre posteriormente otro título. Descubrir es similar a explorar, y bien conocido es el aforismo de Bluntschi: "Explorar es hacer un acto de ciencia, no de política".

Me he detenido en el descubrimiento, porque hay Estados que pretenden fundamentar sus derechos sobre la zona antártica en este falso modo de adquirir, al cual como he dicho, el Derecho Internacional concede un valor muy relativo.

Uno de los modos de adquirir originarios, aceptados por el Derecho Internacional, como es la ocupación, tampoco puede aplicarse de manera perfecta en el caso de las tierras polares.

La ocupación requiere para llevarse a cabo, según lo dejó establecido el Instituto de Derecho Internacional en 1888, en su sesión de Lausanne, que sea real y efectiva, y bien comprendemos que tales condiciones no pueden realizarse en regiones como las polares, inhospitalarias para la vida humana.

Hay otras reglas que rigen la adquisición del dominio en las zonas polares. Y estas reglas, que han sido señaladas por la práctica internacional, se apoyan en dos conceptos fundamentales: la vecindad y una especie de ocupación efectiva. La vecindad otorga derechos preferentes para la ocupación, y esta última, determinada por normas especiales que luego explicaré, da a los mencionados derechos de preferencia, el carácter de derechos efectivos de dominio.

Antes de continuar, debo referirme aquí a la llamada Teoría de los Sectores Polares que tiene íntima relación con el concepto de vecindad, de que he hablado.

Los geógrafos y juristas han aceptado la división del Continente Antártico en cuatro sectores: el americano, el africano, el australiano y el del Pacífico, los tres primeros enfrentados a los respectivos continentes y el cuarto al océano que le da su nombre.

Al sector americano invocan derechos, por su vecindad, Chile y la República Argentina; y sostiene también pretensiones la Gran Bretaña, basándose en su proximidad a las Falklands o 
Malvinas. En el sector africano se disputan soberanía Gran Bretaña y Noruega, apoyando su demanda en el título de descubrimiento. Sobre el sector australiano alegan dominio Australia, Francia y Nueva Zelanda. En el sector del Pacífico han hecho exploraciones los Estados Unidos.

La Teoría de los Sectores Polares, que ya ha tenido, Honorables Senadores, aplicación efectiva en la distribución internacional de las zonas árticas, parte del principio de que son los países vecinos a los aludidos sectores los que tienen derechos preferentes de soberanía sobre ellos, ya que son los que en mejores "condiciones" se encuentran para proceder a su explotación industrial, aprovechando sus riquezas.

Pero la sola vecindad no basta. Es menester que, además, se haya manifestado la voluntad de adquirir, que el Estado interesado y vecino haya ejercido actos que indiquen claramente su ánimo de comportarse como soberano.

¿Cuáles podrán ser tales casos, tratándose de las tierras polares, donde, como he dicho, es difícil mantener la continuidad de ocupación? La respuesta nos la da la jurisprudencia internacional, la última de cuyas manifestaciones ha sido la importante sentencia dictada por la Corte Permanente de Justicia Internacional con fecha 5 de abril de 1933, en el asunto de Groenlandia Oriental.

Según dicha sentencia, que atribuye a Dinamarca, contra las pretensiones noruegas, la soberanía del mencionado territorio, constituyen actos de dominio los que se realicen en ejercicio de actividades económicas, como la pesquería y la caza de ballenas.

La doctrina que fluye de este fallo coincide, por otra parte, con que la que sostienen los tratadistas de Derecho Internacional. Quiero citar únicamente al respecto la opinión de quien fuera ilustrado profesor de esta cátedra y es hoy Senador de la República, don Miguel Cruchaga Tocornal. Dice el señor Cruchaga Tocornal en su reputada obra "Derecho Internacional":

"En las regiones antárticas, las dificultades que presenta la naturaleza se oponen, en general, a una regular ocupación de este género. La ocupación de la Isla Decepción, por súbditos chilenos que se dedican a la pesca de focas, es de las que pueden presentarse como más perfectas ante el derecho".

Nuestro país ha cumplido y cumple con cada una de las condiciones que impone el Derecho Internacional en esta materia. Está favorecido, en primer lugar, por la vecindad, que lo hace ser el país antártico por excelencia, y, en seguida ha propugnado y autorizado, mediante numerosos decretos supremos de concesiones, como lo expondré después, al referirme a los antecedentes administrativos, efectivas actividades económicas en la Antártica Chilena.

Estos títulos jurídicos tienen por sí solos una apreciable importancia; pero si los unimos a los antecedentes históricos que demuestran nuestra soberanía polar, entre éstos al uti possidetis de 1810, adquieren en conjunto un valor incontestable, toda vez que las diferentes manifestaciones de soberanía que representan los actos de ocupación realizados a través de nuestra historia, las 
hicimos precisamente en virtud de habernos considerado siempre dueños y señores, como lo señaló O’Higgins, de las tierras situadas al sur del Cabo de Hornos.

\subsection{Antecedentes diplomáticos}

Antes de referirme a los decretos supremos de concesiones a que aludí, y a otros antecedentes de carácter administrativo, deseo decir dos palabras acerca de algunas actuaciones de orden diplomático en que ha intervenido nuestra Cancillería y que demuestran la constante preocupación del Gobierno de Chile por los asuntos polares.

Ya tuve oportunidad de mencionar una de las más importantes de dichas actuaciones -las gestiones promovidas por los Cancilleres señores Huneeus Gana y Puga Borne en los años de 1906 a 1908-, y de dar a conocer los resultados que alcanzó.

La mayoría de las demás actuaciones diplomáticas se relacionan con la oportuna reserva de derechos que ha formulado nuestro Gobierno cada vez que ha sido notificado de declaraciones de soberanía extranjera sobre el Continente Antártico.

No voy a detenerme en ellas, Honorable Senado; pero quiero solamente destacar las dos últimas verificadas antes de la dictación del Decreto Supremo de noviembre de 1940.

En el mes de marzo de 1939, en respuesta a una nota de la Legación de Noruega en que daba a conocer los límites del sector antártico que se atribuía ese país, el Ministerio de Relaciones Exteriores expresó a dicha representación diplomática:

"Al acusar recibo de la referida nota, tengo el honor de dejar expresamente a salvo todo y cualquier derecho que el Gobierno de Chile pudiera hacer valer sobre los territorios antárticos en cuestión".

Más tarde, en el mes de febrero de 1940, al suscribirse por los países americanos el Acta Final de la Segunda Reunión Consultiva de Ministros de Relaciones Exteriores, celebrada en La Habana, la Delegación de Chile estampó en ese documento la siguiente declaración:

"La Delegación de Chile, en el momento de suscribir la presente Acta Final, además de la reserva expresada en la sesión plenaria privada del día anterior, hace reserva de los derechos de Chile en la Antártica".

El carácter de país polar que puede proclamar Chile ha sido también aceptado internacionalmente, al invitarse a participar en conferencias que han versado sobre tópicos polares. Constituye ello indudablemente un reconocimiento de nuestros intereses en aquellas zonas. 
La última invitación recibida por la Cancillería al respecto, fue la que nos extendió el Gobierno noruego, en junio de 1938, para asistir a la Exposición Polar de Bergen, que iba a tener lugar en 1940, y que posteriormente fue suspendida, en vista de haber estallado la guerra europea.

La Memoria del Ministerio, correspondiente a 1938, expresa sobre el particular lo siguiente:

"Las distintas reparticiones administrativas que fueron consultadas manifestaron al Ministerio que juzgaban la proyectada exposición de la mayor importancia para Chile, atendida nuestra posición geográfica, los estudios realizados, nuestros intereses de todo orden en el Antártico y la amplitud que tenía en el temario".

\subsection{Antecedentes administrativos}

Paso, finalmente, señores Senadores, a hacer una breve relación de los antecedentes de orden administrativo, esto es, del conjunto de actuaciones internas que le han cabido al Gobierno en esta materia y que revisten, según ya expuse, importancia internacional como testimonio que son de nuestro carácter de soberanos sobre la Antártica Chilena.

Las más importantes de dichas actuaciones las constituyen los diversos decretos supremos mediante los cuales el Gobierno otorgó concesiones de pesca y caza de ballenas y otras especies marinas en la región polar. Como lo ha dicho un autor, cada uno de estos decretos es "una nueva afirmación de nuestra soberanía".

El primero de ellos lleva fecha 31 de diciembre de 1902 y fue dictado en favor de don Pedro Pablo Benavides, a quien se concedió en arrendamiento las Islas de Diego Ramírez y San Ildefonso, y se dio autorización de pesca hasta la zona antártica. La concesión Benavides, además de ser la primera hecha por el Gobierno de Chile, es asimismo la primera otorgada por un Gobierno en el mundo, sobre la región antártica.

Más tarde, en 1904, nuestro Gobierno autorizó la existencia de la llamada Sociedad Anónima Industrial, que se formó con propósitos de pesca y caza de ballenas en aguas antárticas.

En febrero de 1906 se otorgó la conocida Concesión Fabry-Toro Herrera, que reviste indudable importancia para nuestros derechos polares, pues los términos en que está redactado el respectivo decreto expresan claramente el concepto de los gobernantes de aquella época en cuanto al ámbito de nuestra soberanía. Autoriza, en efecto, el decreto a los concesionarios para ocupar, entre otras, las islas de Diego Ramírez y Shetlands del Sur y las tierras situadas hacia el Polo, y les obliga a "ejercer los actos administrativos que el Gobierno de Chile juzgue convenientes para el resguardo de sus intereses en las regiones indicadas" y a proteger "los bienes nacionales existentes en aquellas regiones". 
Cabe hacer notar, Honorable Senado, que ni la concesión Fabry-Toro Herrera ni ninguna otra, a pesar de haber sido puestas en conocimiento público, provocó protestas o reclamaciones de algún Gobierno extranjero, circunstancia que comprueba que nuestros derechos de dominio no eran discutidos por nadie.

Otra de las concesiones importantes es la que se extendió en favor de la Sociedad Ballenera de Magallanes, cuya existencia fue aprobada por Decreto Supremo de julio de 1906. Desde su organización hasta 1910, operó la flotilla ballenera de esta sociedad, escogiendo como base de sus actividades la Isla Decepción, que forma parte del Archipiélago de las Shetlands del Sur. Allí encontró Charcot, el famoso médico y explorador francés, en diciembre de 1908, a los esforzados pescadores y cazadores chilenos, y así lo atestigua en su obra "Le Pourquoi-Pas dans l'Antartique".

Reorganizada más tarde, en 1911, la Sociedad Ballenera de Magallanes continuó su labor incansablemente hasta el verano de 1914. El incendio de su base, situada en la Península de Brunswick, vino a interrumpir sus faenas.

Todas estas concesiones fuera de los permisos de pesca otorgados por la Gobernación de Magallanes, revisten, señores Senadores, un alto valor jurídico. Juzgo innecesario insistir sobre ello; pero deseo únicamente poner de relieve estos dos hechos:

$1^{\circ}$ El Gobierno de Chile, al conferir estas autorizaciones, tenía la plena conciencia de su soberanía sobre la zona polar, la cual, como he dicho, no fue objetada internacionalmente; y

$2^{\circ}$ Los Actos de ocupación llevados a cabo por los balleneros y pescadores chilenos, representan una firme consolidación de nuestros derechos antárticos, de acuerdo con las normas del Derecho Internacional.

Dije al empezar esta parte de mi exposición que, una vez explicados los antecedentes que dieron origen al decreto supremo dictado el 6 de diciembre de 1940, me refería a la repercusión internacional de dicha medida de nuestro Gobierno, y de esto quiero ocuparme a continuación.

Tan pronto como se dictó el mencionado decreto dispuso la Cancillería que fuese dado a conocer simultáneamente al país y a los Gobiernos extranjeros.

La prensa nacional, junto con difundir su texto, proporcionó amplias informaciones acerca de los títulos de Chile sobre el sector polar delimitado, y aprobó, sin excepciones, la trascendental medida adoptada. 
En cuanto a los Gobiernos extranjeros, tanto americanos como extra-continentales, fueron notificados por conducto de nuestras representaciones diplomáticas, en el exterior, a las que se instruyó cablegráficamente en tal sentido. Por razones obvias, el decreto fue dado a conocer a los Gobiernos de la República Argentina y de los Estados Unidos por medio de sus Embajadas en Santiago.

De todas las naciones notificadas, solo cuatro formularon objeciones al decreto chileno; ellas fueron: Gran Bretaña, los Estados Unidos, Japón y la República Argentina.

Gran Bretaña fundamentó su objeción en la circunstancia de que, según sus pretensiones, una parte de la Antártica Chilena se superpone al sector polar inglés que ha denominado "Dependencias de las Islas Falkland”. Este sector británico comprendería, además de la Tierra de O’Higgins, las Islas Shetlands, Georgias y Orcadas del Sur.

Nuestro país ha respondido al Gobierno de Gran Bretaña que las llamadas "Dependencias de las Islas Falkland" fueron establecidas por Letras Patentes en 1908 y 1917, esto es, cuando hacía seis y quince años que el Gobierno de Chile había confirmado su soberanía antártica mediante actos de ocupación efectiva, soberanía que, como ya lo he expuesto, tiene su origen en Reales Cédulas de la Corona Española.

Los Estados Unidos, por su parte, expresaron que nunca han reconocido demandas de soberanía de ninguna nación en el Polo Sur, y formularon, al propio tiempo, formal reserva de sus derechos sobre esa zona. Esta actitud del Gobierno norteamericano responde, por otra parte, a una línea permanente de su política internacional. Hace pocos días, el 28 de diciembre pasado, el Secretario de Estado subrogante, señor Dean Acheson, ha insistido sobre ella al manifestar que su Gobierno "no ha reconocido ninguna reivindicación territorial en la Antártica hecha por cualquiera nación, y se reserva el derecho a discutir dichas reivindicaciones en el futuro".

El Departamento de Estado sugirió asimismo, en su nota al Gobierno de Chile, la celebración de una conferencia especial de países americanos con intereses polares, a fin de determinar en ella, de acuerdo con los principios del Derecho Internacional, sus respectivas pretensiones y llegar a un acuerdo sobre la materia.

Japón también presentó reservas al decreto chileno, sin manifestación de razones. Dichas reservas fueron rechazadas por nuestra Cancillería en una comunicación, que, entre otros, expresa los siguientes conceptos:

"El Gobierno de Chile no alcanza a divisar los fundamentos con que el Gobierno del Japón hace una reserva de derechos en un triángulo que, partiendo de mares y tierras que pertenecen a la República de Chile, va a morir con su vértice en el Polo Sur; está situado dentro de la Antártica Americana; abarca regiones poseídas por Chile desde muy antiguo, y deslinda al Este y al Oeste con zonas ocupadas por la Argentina y los Estados Unidos”.

Número de página no utilizable para citar 
Por lo que toca a la República Argentina, su Gobierno hizo observaciones con respecto al meridiano $53^{\circ}$ de longitud oeste de Greenwich, que señala el límite oriental de la Antártica Chilena, sin pretender negar, con todo, los títulos de nuestro país a un sector de la zona polar sur. Después de un cambio de notas entre ambas Cancillerías, invitamos al Gobierno argentino a debatir amistosamente y con carácter técnico el asunto y estudiar la manera de encontrar una línea común de vecindad entre nuestras dos soberanías. La invitación de Chile fue aceptada, y, en tal virtud, se celebraron en Santiago, en el mes de marzo de 1941, las conversaciones de los delegados de las Comisiones Antárticas chilena y argentina. Como representantes de la Comisión Chilena actuó el señor don Julio Escudero, miembro integrante de la misma y Profesor de Derecho Internacional Público de la Universidad de Chile y como delegado de la Comisión Argentina, el doctor don Isidoro Ruiz Moreno, Presidente de ella y Consejero Jurídico del Ministerio de Relaciones Exteriores y Culto.

Las referidas conversaciones se llevaron a efecto dentro de un amplio espíritu de cordialidad, y a través de ellas quedó abierto y manifiesto el fraternal y sincero deseo de alcanzar un pronto y completo entendimiento en esta importante materia.

No quedó en estas conferencias agotado el estudio del asunto y con tal motivo, y a fin de poder reunir mayores antecedentes sobre el particular, los delegados acordaron aconsejar a sus Gobiernos la prosecución de las conversaciones dentro del más breve plazo posible. El señor Ruiz Moreno al término de esta primera etapa de la gestión, hizo invitación formal, en nombre de su Gobierno, para que las conferencias se continuaran en la ciudad de Buenos Aires, y así quedó establecido en las actas y comunicados que ambas Cancillerías entregaron a la prensa con fechas 26 y 29 de marzo de 1941.

La negociación Escudero-Ruiz Moreno, después de una extensa confrontación de puntos de vista, dejó establecidas las siguientes conclusiones: $1^{\circ}$ Que existe una Antártica Sudamericana, y $2^{\circ}$ Que los únicos países con derechos exclusivos de soberanía sobre ella son Chile y la República Argentina.

Han transcurrido desde entonces poco menos de seis años sin que las conversaciones pudieran reanudarse, según está acordado. La guerra mundial y la situación política de la República Argentina han sido las causas determinantes de este aplazamiento. Eliminadas en la actualidad dichas causas el Gobierno de esa nación ha manifestado últimamente deseos de continuar las negociaciones, para lo cual el Gobierno de Chile se encuentra en disposición favorable.

Es de esperar, en consecuencia, que dentro de breve tiempo se reinicie en Buenos Aires la gestión pendiente desde 1941. 


\section{Señor Presidente:}

Después de dar a conocer al Honorable Senado, en sus líneas generales, los diversos antecedentes relacionados con la cuestión antártica y las actividades que hasta el momento ha desarrollado nuestro país a su respecto, deseo referirme ahora a la futura política que en esta materia se propone llevar adelante el Gobierno, y cuyo primer paso lo constituye la expedición oficial que en breves días más llegará hasta la región polar chilena.

El proyecto de una expedición de esta naturaleza, con objetivos científicos y de reafirmación del dominio nacional, había sido considerado por el Gobierno desde hace ya largos años. Desgraciadamente, no fue posible, por diversas circunstancias, llevarlo hasta ahora a la práctica.

En efecto, correspondió en 1906 al Ministro de Relaciones Exteriores de la época, don Antonio Huneeus Gana, tomar la iniciativa en tal sentido, y a este fin, envió al Congreso Nacional, un proyecto de ley en que solicitaba la suma de \$150.000 para atender a ese gasto. El señor Huneeus Gana constituyó también una Comisión Antártica destinada a efectuar los preparativos de la expedición. El viaje, sin embargo, no llegó a realizarse, debido a la catástrofe nacional que significó el terremoto de 1906 y a que posteriormente el titular de la cartera abandonó el Ministerio junto con terminar su periodo el Presidente Riesco.

En 1916, dolorosas circunstancias obligaron al Gobierno a enviar un barco de nuestra Marina al territorio antártico. Recordarán los Senadores que en esta fecha, el piloto de nuestra Armada, Luis Pardo, arribó en la escampavía "Yelcho" a la Isla del Elefante, una de las Shetlands del Sur, desafiando el rigor del invierno polar, con el humanitario objetivo de salvar a la expedición Shakleton, lo que consiguió tras denodados esfuerzos.

Las naves en que habrá de realizarse la expedición enviada este año, por el Gobierno, son el transporte "Angamos" y la fragata "Iquique".

Como vanguardia de la expedición, la "Iquique" partió de Punta Arenas en la noche del 15 de este mes, en dirección a las Shetlands, donde esperará la llegada del "Angamos” que saldrá de Valparaíso a fines de enero.

A bordo de este último barco viajará una completa misión científico-naval-militar, compuesta de representantes de las Fuerzas Armadas, geólogos, glaciólogos, meteorologistas, expertos en ballenería y fauna marina y técnicos en otras importantes especialidades. Irán también un miembro del Honorable Senado, uno de la Honorable Cámara de Diputados, un representante del Ministerio de Relaciones Exteriores, e igualmente algunos periodistas.

De acuerdo con un compromiso contraído en 1943 con la República Argentina, que en el indicado año invitó a tres oficiales de nuestra Armada a participar en el crucero que efectuó a la zona polar el transporte argentino "Primero de Mayo" viajarán asimismo en el "Angamos" tres oficiales navales de esa nacionalidad. 
Con propósitos científicos y a objeto de llevar a cabo una manifestación más de efectivo ejercicio de nuestra soberanía sobre la Antártica Chilena, se dejará establecida en este viaje una base meteorológica y magnética, cuya ubicación en territorio antártico se determinará allí mismo y que quedará a cargo de un oficial de Marina y de siete u ocho hombres de tropa. A este fin, se transportarán en el "Angamos" todos los necesarios elementos para la construcción del mencionado observatorio, así como de la vivienda del personal, el cual será relevado anualmente. Cabe advertir que la República Argentina tiene también instalada una base de esta especie en la Isla Laurie, del Archipiélago de las Orcadas del Sur, que queda fuera de nuestro sector.

Como una constancia gráfica de nuestro dominio, la expedición dejará en diferentes sitios del territorio antártico, marcas y señales que proclamen los derechos de Chile. Es ésta una práctica que viene siendo puesta en uso desde las primeras exploraciones polares, y nos ha parecido conveniente adoptarla, pues da a conocer a ojos extranjeros la efectividad de la ocupación y el ámbito que abarca la soberanía.

La expedición contará también con tres aviones, con los cuales hay el propósito de incursionar hasta la zona más austral que lo permitan las condiciones climatéricas.

En resumen, este primer viaje oficial chileno al casquete antártico, ha sido preparado por la Armada Nacional en forma completa y acuciosa, y el Gobierno abriga la absoluta certeza de que será de positivos beneficios para el país, tanto porque representa un nuevo acto de soberanía de la República sobre el extremo sur de nuestro territorio, como porque significará un mejor conocimiento científico, estratégico y económico de estas regiones.

Además de Chile, saben los señores Senadores, por las informaciones que ha dado la prensa, que siete otras naciones han organizado igualmente, para este verano, cruceros de expedición al Polo Sur, las cuales han arribado ya o arribarán próximamente a diferentes puntos del extenso Continente Antártico. Las naciones en referencia son: los Estados Unidos, Gran Bretaña, la Unión Soviética, Noruega, Nueva Zelanda, Australia y la República Argentina.

Los Estados Unidos han preparado dos expediciones: una oficial, comandada por el Almirante Richard E. Byrd, y cuya base de operaciones se ha situado en la llamada Pequeña América, del sector del Pacífico; y otra particular, pero patrocinada por las autoridades norteamericanas, que dirige el comandante en retiro, señor Finn Ronne, quien ha puesto en conocimiento de nuestro Gobierno que hará observaciones científicas en la Tierra de O’Higgins.

Gran Bretaña nos ha comunicado que algunos grupos de reconocimiento de las Dependencia de las Islas Falkland, se encuentran actualmente en diferentes puntos de nuestro sector antártico, y ha ofrecido la colaboración y ayuda de estos grupos a los expedicionarios chilenos. En nota pasada hace pocos días a la Embajada de Su Majestad Británica, el Ministro que habla, junto con agradecer el ofrecimiento, ha declarado que Chile da valor de actos de mera tolerancia a las 
incursiones de dichos grupos, por haberse realizado en lugares que forman parte de nuestro territorio nacional.

No es este viaje oficial el único acto que hemos realizado en defensa de nuestros derechos territoriales en la Antártica. En estos dos últimos meses, ha querido el Gobierno reparar el silencio que en torno de este importante problema se había producido desde hacía algunos años.

En el orden administrativo, se han adoptado las siguientes medidas:

1.- Incorporación del Territorio Chileno Antártico a la división político-administrativa de la República, mediante un proyecto de ley que estudia en estos momentos el Ministerio del Interior.

2.- Revisión de textos escolares de geografía e historia en forma de que la representación gráfica y descripción de nuestro territorio, así como los antecedentes históricos respectivos, aparezcan claramente expuestos.

3.- Emisión de una serie de sellos de correo referentes a la Antártica Chilena, cuya autorización ya ha sido dada por Decreto $\mathrm{N}^{\circ}$ 6.378, de 4 de diciembre de 1946, del Ministerio del Interior.

Por lo que toca al aspecto de política internacional, buscamos como ya dije, un acuerdo con la República Argentina, y a este fin responderá la prosecución de las conversaciones técnicas entre ambos países, pendientes desde 1941.

Es indudable que una doctrina netamente americana cobra, en las regiones antárticas próximas a nuestro continente, una excepcional importancia. Me refiero a la Doctrina Monroe.

La aplicación de la Doctrina Monroe a dichas regiones, es una consecuencia de los antecedentes geográficos a que antes hice alusión, y de ser aceptada, ella excluiría toda pretensión de soberanía de naciones no americanas

Como puede apreciarlo, pues, el Honorable Senado, la cuestión antártica, a pesar del valor incuestionable de nuestros claros títulos de todo orden, presenta modalidades que no hacen fácil una adecuada solución.

Nos espera en esta materia una larga labor. Pero deben saber el país y el Honorable Senado, que el Gobierno de la República no se dará reposo ni omitirá esfuerzos para obtener el pleno reconocimiento internacional de nuestros derechos de dominio. 
Señor Presidente:

Antes de dar termino a esta exposición sobre la cuestión antártica, creo necesarias algunas consideraciones acerca del valor que representa el sector polar chileno, en cuanto a las riquezas y posibilidades que encierra.

En primer lugar, es sabido que los mares antárticos constituyen en la actualidad la más importante reserva de ballenas en el mundo, en particular los mares que rodean la Antártica Americana. De acuerdo con las estadísticas, en la temporada de caza 1937-1938, de 54.664 ballenas cazadas en todo el mundo, 46.039 lo fueron en la región antártica. Cada ballena, de las del tipo llamado azul, produce hasta 25 toneladas de aceite, que, sobre la base del precio actual de $\$ 10$ por litro, representa la suma de $\$ 250.000$ por animal, y esto sin contar la carne, los huesos, las barbas, etc. El aceite de ballena es empleado en la fabricación de la margarina, de jabones, de velas y de explosivos y tiene, además, usos medicinales.

Es de hacer notar que, como resultado de las actividades bélicas que paralizaron por seis años las labores de caza, el cetáceo antártico se ha reproducido en forma sorprendente.

Tiene, asimismo, la Antártica Chilena, un innegable valor estratégico. La tierra de O’Higgins y la Tierra del Fuego, forman dos espolones que son los verdaderos guardianes, por así llamarlos, del Estrecho de Drake, vale decir, del tercer paso marítimo que une los Océanos Pacífico y Atlántico. Dos de estos pasos se hallan en manos de nuestro país: el citado Estrecho de Drake y el Estrecho de Magallanes. Aparte de ello, a la Tierra de O’Higgins ha de corresponder en el futuro, cuando se establezcan líneas de navegación aérea transpolar, como se ha proyectado, un papel preponderante en el tráfico internacional.

Finalmente, se ha comprobado que el suelo mismo antártico contiene importantes riquezas. Me limitaré a citar la opinión oficial del Almirante Richard E. Byrd, expresada en la Cámara de Representantes de los Estados Unidos. Allí, el célebre explorador norteamericano manifestó que han sido encontrados en la Antártica, por varias expediciones, carbón, petróleo y 141 distintos minerales. Agregó que, entre estos últimos podía mencionar como existentes la plata, que se ha hallado en mezcla con piritas de zinc, el oro, el hierro, el cobre y el antimonio, además del molibdeno.

El territorio antártico encierra, como se ha visto, indudables riquezas y posibilidades. Pero aun cuando nada valiera, aun cuando en su sector chileno no fuera más que la fría y desolada prolongación de la Patria, existiría de parte nuestra la obligación de conservarlo y defenderlo, precisamente por eso: por ser el confín austral de Chile, parte integrante de su suelo.

Número de página no utilizable para citar 
Revista Tribuna Internacional

Volumen $6 \cdot \mathrm{N}^{\mathrm{o}} 11 \cdot 2017$

ISSN 0719-482X (versión en línea)

Soy de los que creen que el patrimonio nacional, cualquiera que sea su importancia, hay que mantenerlo intacto, tal cual lo recibimos de nuestros próceres, y entregarlo en igual forma a las generaciones venideras. En esta patriótica vigilia, el Ministro de Relaciones Exteriores está seguro de contar con el aliento y el esfuerzo de todos los chilenos. 